\title{
MICRORNAS AS DIAGNOSTIC AND PROGNOSTIC BIOMARKERS
}

\author{
Albena Alexandrova \\ Institute of Neurobiology, Bulgarian Academy of Sciences
}

The intensive development of molecular biology and biochemistry in recent years has allowed the disclosure of intimate mechanisms of a number of processes in the cell. Numerous molecules have become useful tools for diagnosing and predicting a number of diseases. These are, for example, the small, non-coding micro RNAs (miRNAs). It was found that the majority of protein-coding genes contain miRNA-binding sites under selective pressure (1) that make them the master regulators of cellular processes. Thus, the misexpression of miRNAs is associated with many pathological processes, including all cancers, as well as metabolic, cardiovascular, neuronal and immune-related diseases (2). In addition, miRNAs could be excreted outside cells from which they were transcribed. In humans, extracellular RNAs (exRNAs) have been discovered in bodily fluids, such as venous blood, saliva, breast milk, urine, semen, nasal secretion, and vaginal fluid (3). Playing a role in intercellular communication and cell regulation, they are a rich source of information about cellular processes in both health and disease. Numerous data have shown that exRNAs may serve as diagnostic and prognostic biomarkers of cancer (4), cardiovascular (5) and neurodegenerative diseases (6).

Since the expression patterns of small RNAs have a potential as diagnostic, prognostic, and treatment response biomarkers, their intact extraction is essential. Current RNA testing involves isolation of RNA usually from patient's blood samples via standard venipuncture or extraction from formalin-fixed, paraffinembedded (FFPE) tissue samples, and then detecting RNA expression patterns in real time using polymerase chain reaction (PCR). The clinical importance of FFPE samples consists of retrospective analysis of archival tissue that enables the correlation of molecular findings with the response to treatment and the clinical outcome. However, the isolation of quality RNA from FFPE specimens is quite complicated, because the fixation process causes cross-linkage between nucleic acids and proteins, and covalently modifies RNA by the addition of monomethyl groups to the bases. As a result, the molecules are rigid and susceptible to mechanical shearing, and the cross-links may compromise the use of RNA as a substrate for reverse transcription (7). In order to maintain the integrity of the DNA during the isolation procedure other methods such as proteinase $\mathrm{K}$ lysis or precipitation with phenol-based reagents are used. Nowadays, most scientists use commercial nucleic acid extraction kits based on spin column technology. Spin columns contain a silica resin that selectively binds DNA or RNA, depending on salt conditions and other factors influenced by the extraction method. The result is high quality material for cloning, long range sequencing and long read sequencing, to name a few potential applications.

Data on comparative analysis of the various methods for isolating intact RNA are much needed to assess their advantages and disadvantages and apply the most appropriate method in order to use the microRNAs for reliable prediction, early detection and therapeutic response of disease states. Therefore, articles such as that of Dimaras et al. that discuss the efficacy of RNA purification and recovery by applying traditional and modern methods are timely and useful and give new guidance in methodological work.

\section{REFERENCES}

1. Friedman RC, Farh KK, Burge CB, Bartel DP. Most mammalian mRNAs are conserved targets of microRNAs. Genome Res. 2009;19(1):92-105. doi: 10.1101/gr.082701.108

2. Chang TC, Mendell JT. microRNAs in vertebrate physiology and human disease. Annu Rev Genomics Hum Genet. 2007;8:215-39. doi: 10.1146/annurev.genom.8.080706.092351 


\section{EDITORIAL}

3. Witwer KW, Buzás EI, Bemis LT, Bora A, Lässer C, Lötvall J, et al. Standardization of sample collection, isolation and analysis methods in extracellular vesicle research. J Extracell Vesicles. 2013;2. doi:10.3402/jev.v2i0.20360.

4. Chen X, Ba Y, Ma L, Cai X, Yin Y, Wang K, et al. Characterization of microRNAs in serum: a novel class of biomarkers for diagnosis of cancer and other diseases. Cell Res. 2008;18(10):997-1006. doi: 10.1038/cr.2008.282

5. D’Alessandra Y, Devanna P, Limana F, Straino S, Di Carlo A, Brambilla PG, et al. Circulating microRNAs are new and sensitive biomarkers of myocardial infarction. Eur Heart J. 2010;31(22):2765-73. doi: 10.1093/eurheartj/ ehq16

6. Witwer KW, Sarbanes SL, Liu J, Clements JE. A plasma microRNA signature of acute lentiviral infection: biomarkers of CNS disease. AIDS. 2011;25(17):2057-67. doi: 10.1097/QAD.0b013e32834b95bf

7. von Ahlfen S, Missel A, Bendrat K, Schlumpberger M. Determinants of RNA quality from FFPE samples. PLoS One. 2007;2(12):1261. doi: 10.1371/journal.pone.0001261 